\title{
WYKAZ ODCZYTÓW ORAZ IMPREZ NAUKOWYCH I KULTURALNYCH ZORGANIZOWANYCH PRZEZ ODDZIAŁY TOWARZYSTWA Literackiego im. AdAma MiCKieWiCZA W ROKU 2014
} (Na podstawie sprawozdań oddziąów SporządZiŁa Iwona WiśniewsKa)

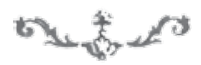

\section{BIA ŁYSTOK}

Sympozjum międzykulturowe „Sokrat Janowicz - pisarz transgraniczny” (zorganizowane wraz z Zespołem Badań Regionalnych oraz Katedrą Kultury Białoruskiej Uniwersytetu w Białymstoku, wsparte dotacją Urzędu Marszałkowskiego Województwa Podlaskiego) poświęcone biografii, działalności i pisarstwu lidera podlaskich Białorusinów.

Opracowanie i współwydanie książki Sokrat Janowicz - pisarz transgraniczny. Studia, wspomnienia, materiały, pod red. G. Charytoniuk-Michiej, K. Sawickiej-Mierzyńskiej, D. Zawadzkiej, Białystok 2014. Publikacja zawiera rozprawy naukowe, eseje i wywiady w języku polskim i białoruskim inspirowane życiem i twórczością Sokrata Janowicza.

\section{BYDGOSZCZ}

Prelekcje i dyskusje z cyklu comiesięcznych „Spotkań wtorkowych”:

Dr Jarosław Bytner, Polski esej historyczny. Preteksty monograficzne

Dr hab. Ireneusz Szczukowski, prof. nadzw., Strategie czytania literatury polskiego renesansu i baroku

Dr Aleksandra Norkowska, Scalanie obrazów, czyli o potrzebie i sposobach odkrywania miasta w piśmiennictwie polskiego wieku świateł

Prof. dr hab. Rolf Fieguth, Dialog Norwida z Krasińskim, czyli pożegnanie z romantyzmem oraz Gombrowicz z niemiecka gęba

Prof. Aleksiej Wasiliew, Memory studies wobec pamięci zbiorowej oraz Tryumf i trauma - dwa bieguny pamięci

Oddział Bydgoski TLiAM stale współpracuje z Uniwersytetem Kazimierza Wielkiego, na którego terenie znajduje się siedziba Oddziału. 
Przy Oddziale Bydgoskim działają aktywnie dwie ogólnopolskie Komisje Towarzystwa:

Kom isja Komparatystyczn a pod przewodnictwem prof. dr hab. Lidii Wiśniewskiej. W ramach prac Komisji 27-28 marca 2014 zorganizowano (we współpracy z Uniwersytetem Kazimierza Wielkiego) seminarium naukowe „Mity i komparatystyka”. Wystąpienia wygłosili: prof. dr hab. Lidia Wiśniewska (Wstęp); dr hab. Barbara Tomalak (Mityczne konteksty i podteksty funkcjonowania społeczeństwa polskiego u poczatku wieku XXI); dr hab. Stanisław Jasionowicz, prof. UP im. KEN (Wojny mitów w (zmediatyzowanym) świecie współczesnym); dr Mirosław Gołuński (Mit $i$ historia); dr hab. Zbigniew Kaźmierczyk, prof. UG (Kreacja i subkreacja w analizie komparatystycznej); dr Marta Kładź-Kocot (Mity - od logiki prefiguracji do doświadczenia dyspersyjnego); prof. dr hab. Lidia Wiśniewska (Mity Boga i Natury w opisie świata). Podczas seminarium przeprowadzono też dyskusję nad perspektywami komparatystyki mitoznawczej i zainicjowano prace nad kolejnym tomem z serii „Komparatystyka między Mickiewiczem a dniem dzisiejszym”, zatytułowanym $W$ stronę komparatystyki mitograficznej.

Komisja Dydaktyczna kontynuowała rozpoczętą w 2012 roku inicjatywę dyskusji na temat edukacji polonistycznej. W 2014 roku ukazało się trzytomowe wydawnictwo zawierające materiały z Kongresu Dydaktyki Polonistycznej, który odbył się w listopadzie 2013 w Krakowie. Wydawnictwo zawiera także głosy, które wypracowano podczas cyklicznych spotkań dydaktyków uniwersyteckich i nauczycieli szkół średnich organizowanych i prowadzonych przez prof. dr hab. Lidię Wiśniewską pod nazwą Małe Forum Edukacyjne Towarzystwa Literackiego im. Adama Mickiewicza.

Komisja Dydaktyczna pod przewodnictwem mgr Anny Nakielskiej-Kowalskiej prowadzi nieprzerwaną działalność w formie warsztatów i wykładów dla szkół ponadgimnazjalnych w Bydgoszczy. W 2014 roku warsztaty i wykłady w V, VI i VII Liceum Ogólnokształcącym prowadzili dr Mirosław Gołuński i dr Marta Kładź-Kocot.

\section{CZĘSTOCHOWA}

Prelekcje i dyskusje w ramach otwartych zebrań naukowych Oddziału Częstochowskiego:

Dr hab. Ireneusz Sikora, prof. AJD, „W Tobie nadzieję kładę”. Eliza Orzeszkowa czyta Kochanowskiego

Dr Krzysztof Czajkowski, Tradycje sentymentalizmu w twórczości Antoniego Malczewskiego

Dr hab. Kazimiera Szymańska, Miejsce i funkcje muzyki w życiu zesłańców syberyjskich (na podstawie relacji pamiętnikarsko-wspomnieniowych Szymona Tokarzewskiego) 
Dr hab. Agnieszka Czajkowska, prof. AJD, Filomaci w szkole Śniadeckich. Zwiazki nauki i literatury w I połowie XIX wieku

Mgr Jadwiga Wrzaszczyk, Los Polaków zesłanych na Syberię w okresie II wojny światowej. Wspomnienia częstochowskiej nauczycielki, pani Aleksandry Siedleckiej

Dr Barbara Kubicka-Czekaj, Literackie rozważania o szczęściu (wykład wygłoszony podczas zorganizowanego przez Częstochowski Oddział TLiAM uroczystego jubileuszu z okazji 65-lecia pracy naukowej dr Barbary Kubickiej-Czekaj; uroczystość odbyła się 22 października w Ośrodku Promocji Kultury „Gaude Mater” w Częstochowie)

Mgr Maria Wyporska, W kręu literackiej twórczości Jana Pawła II Mgr Ewelina Mika, Wspomnieniowe pisarstwo historyczne Marii Czapskiej

Oddział Częstochowski był współorganizatorem (wraz z Akademią im. Jana Długosza i Muzeum Częstochowskim) jubileuszu 25-lecia pracy w Akademii im. Jana Długosza oraz działalności na rzecz Kultury Częstochowy dr hab. Elżbiety Hurnik, prof. AJD. Uroczystość odbyła się 25 czerwca 2014 roku w Muzeum Częstochowskim.

\section{GDAŃSK}

Wykład dr hab. Grażyny Tomaszewskiej, prof. UG, Czytanie i szczęście oraz promocja jej książki Zagubiona przestrzeń i co dalej... (Gdańsk 2013).

Panel dyskusyjny (zorganizowany we współpracy z Teatrem Muzycznym w Gdyni, na Nowej Scenie im. M. Korwina, prowadzony przez prof. dra hab. Jana Ciechowicza) „Powieść na scenie (musicalowej)”. Punktem wyjściowym dyskusji była musicalowa wersja Chłopów Władysława Reymonta.

Spotkanie z prof. dr hab. Zofią Zarębianką, autorką książki Wtajemniczenia (w) Miłosza (Kraków 2014), połączone z dyskusją nad książką (spotkanie prowadzone przez dra hab. Artura Żywiołka towarzyszyło międzynarodowej konferencji „Religijność Czesława Miłosza”, która odbyła się na Wydziale Filologicznym Uniwersytetu Gdańskiego w październiku 2014).

Wykład prof. dra hab. Rolfa Fiegutha O recepcji Gombrowicza w Niemczech $i$ we Francji.

\section{GORZÓW WIELKOPOLSKI}

Zorganizowanie pod patronatem Lubuskiego Kuratora Oświaty otwartego konkursu dla uczniów gimnazjów województwa lubuskiego - „Czytanie warte zachodu”. Cele konkursu: promowanie polskiej literatury współczesnej, propagowanie czytelnictwa i rozwijanie zainteresowań humanistycznych wśród młodzieży. Zawody odbyły się w marcu i w kwietniu 2014 w Gorzowie Wielkopolskim, do pierwszego etapu szkolnego zgłoszono prawie pół tysiąca uczniów, do etapu drugiego zakwalifikowano 171 gimnazjalistów, do finału weszło 28 osób. Laureaci, zgodnie z zarządzeniem Lubuskiego Kuratora Oświaty, uzyskali 7 punktów rekrutacyjnych do szkół publicz- 
nych. Ponieważ konkurs cieszył się ogromnym zainteresowaniem, pod koniec 2014 roku ogłoszono drugą edycję.

\section{JAROSŁAW}

Imprezy zorganizowane we współpracy z Burmistrzem Miasta Jarosławia, Centrum Kultury i Promocji w Jarosławiu oraz Miejskim Ośrodkiem Kultury w Jarosławiu: Spotkanie literackie „Czesława Miłosza portret wielokrotny”. Twórczość autora Doliny Issy zaprezentowali dr hab. Zenon Ożóg, prof. UR, i dr Jan Wolski z Uniwersytetu Rzeszowskiego. Spotkanie uświetniono wystawieniem sztuki Aleksandra Fredry Pierwsza lepsza w inscenizacji zespołu teatralnego Baccalaureus.

Wykład dr Magdaleny Boczkowskiej Inna rzeczywistość. Wisława Szymborska i jej niezwykłe światy.

Spotkanie literackie z Krystyną Lenkowską, poetką i tłumaczką.

Oddział współorganizuje od lat coroczny Regionalny Konkurs Recytatorski i Poetycki im. Jerzego Hordyńskiego, którego celem jest pogłębianie wiedzy o mieście i regionie.

\section{KIELCE}

Prelekcja:

Dr hab. Piotr Pietrych, O zapomnianych motywach i wierszach zawartych w wydanym w 1947 roku „Niepokoju” Tadeusza Różewicza

\section{KRAKÓW}

Współorganizacja spotkania popularnonaukowego „Oświecenie - oblicza piękna”. Referaty przedstawili: dr hab. Roman Dąbrowski, dr Dominika Świątoniowska i mgr Judyta Stępień.

W grudniu - jak co roku - Oddział Krakowski współorganizował Adamowe - spotkanie młodzieży studenckiej i doktorantów Wydziału Polonistyki Uniwersytetu Jagiellońskiego, badaczy i miłośników romantyzmu, wskrzeszające tradycję, obyczaje i świat wartości młodzieży filomackiej. W 2014 roku upamiętniono także 18o. rocznicę wydania Pana Tadeusza.

\section{LUBLIN}

Oddział zorganizował wraz z Muzeum Lubelskim szóstą ogólnopolską konferencję naukową z cyklu „Świat Wincentego Pola” - „Natura i naturaliści” (kwiecień 2014), podczas której wygłoszono dwanaście referatów. Jako plon piątej oraz szóstej konferencji ukazała się wydana przez Wydawnictwo Zamku Lubelskiego książka Świat Wincentego Pola. Język i kultura. Natura i naturaliści (Lublin 2014). 
Cykl spotkań dla młodzieży licealnej (zorganizowanych wspólnie z Muzeum Lubelskim oraz Klubem Kolekcjonerów i Kultury Łowieckiej) „Czytanie Roku myśliwca Wincentego Pola”. Podczas comiesięcznych warsztatów polonistycznych czytano i analizowano kolejne części utworu, lekturze towarzyszyła gawęda literacka.

Wykład dr Agnieszki Bąbel i mgr Agaty Grabowskiej-Kuniczuk Nie od razu „Kroniki” wydano... Uwagi o przygotowaniu edycji wyboru „Kronik” Bolesława Prusa pt. „W Warszawie”.

Wykład dr Estery Lasocińskiej „Najlepsza rzecza umiar”. Motywy epikurejskie w „Pieśniach" Jana Kochanowskiego.

\section{ŁÓDŹ}

Cykl spotkań i warsztatów literackich w ramach Akademii Literatury Polskiej (organizowanych we współpracy z Katedrą Literatury Polskiej XX i XXI wieku Uniwersytetu Łódzkiego). W ramach cyklu zorganizowano:

Otwarte spotkanie i rozmowę z Piotrem Pazińskim oraz warsztaty literackie dla studentów filologii polskiej i innych kierunków humanistycznych.

Dyskusję wokół książki prof. dra hab. Włodzimierza Boleckiego Modalności modernizmu (Warszawa 2012).

Otwarte spotkanie z Janem Gondowiczem poświęcone zagadnieniom twórczości literackiej oraz warsztat literacki dla studentów filologii polskiej i kulturoznawstwa.

Otwarte spotkanie z Wiesławem Myśliwskim poświęcone twórczości pisarza.

\section{OLSZTYN}

Ogólnopolska konferencja naukowa (zorganizowana we współpracy z Zakładem Literatury Współczesnej Uniwersytetu Warmińsko-Mazurskiego) „XXI wiek w literaturze" (kwiecień 2014). W konferencji wzięło udział blisko sześćdziesięciu badaczy $\mathrm{z}$ wielu ośrodków naukowych Polski. Materiały pokonferencyjne wydane zostały w formie książki zbiorowej: Literatura na progu XXI wieku, red. J. Chłosta-Zielonka i Z. Chojnowski, Olsztyn 2014.

Współorganizacja trzeciej edycji konkursu literackiego „O Trzcinę Kortowa”, adresowanego do młodzieży szkół średnich województwa warmińsko-mazurskiego.

\section{OPOLE}

Ogłoszenie konkursu literackiego dla uczniów szkół gimnazjalnych i ponadgimnazjalnych województwa opolskiego „Mickiewicz czytany - Mickiewicz oglądany” na esej lub rozprawkę interpretującą dzieła poety lub też na komentarz krytyczny do dzieła, przedstawienia lub filmu inspirowanego twórczością autora Pana Tadeusza. Konkurs współorganizowany wraz z Regionalnym Centrum Rozwoju Edukacji w Opolu. 
Projekty i wykłady organizowane we współpracy z Miejską Biblioteką Publiczną w Opolu:

Cykliczny projekt (XI edycja) dra Adriana Glenia i dr hab. Jacka Gutorowa, prof. UO w roku 2014 zatytułowany „Proza pamięci Wiesława Myśliwskiego”, obejmujący konkurs na esej dla licealistów i studentów oraz warsztaty poświęcone dziełu autora $\mathrm{Na}$ giego sadu.

Współorganizacja kolejnej edycji Opolskiej Jesieni Literackiej.

Wykłady wygłoszone przez dra Adriana Glenia w Opolu:

O poezji Juliana Kornhausera

Religijność poetów współczesnych

\section{PIOTRKÓW TRYBUNALSKI}

Cykl wykładów wygłoszonych przez dr hab. Barbarę Szargot oraz dra hab. Macieja Szargota, prof. UJK, poświęconych różnym zagadnieniom literatury polskiej dla studentów niepolonistów, zorganizowany we współpracy z Górnośląską Wyższą Szkołą Pedagogiczną im. Kardynała Augusta Hlonda w Mysłowicach.

\section{POZNAŃ}

Imprezy zorganizowane we współpracy z Domem Literatury Biblioteki Raczyńskich: Prezentacja czasopisma „Arttak. Sztuki Piękne”, prowadzenie: Maciej Mazurek i Paweł Czapczyk.

Wieczór autorski i promocja książki dra hab. Marka Pacukiewicza Grań kultury, transgresje alpinizmu (Kraków 2012), prowadzenie: dr hab. Wiesław Ratajczak, prof. UAM.

Wieczór autorski i promocja książki prof. dr hab. Hanny Suchockiej Rzymskie pasje. Kościoły Stacyjne Wiecznego Miasta (Izabelin-Warszawa 2013), prowadzenie: dr hab. Wiesław Ratajczak, prof. UAM.

Prelekcja dr Ewy Płomińskiej-Krawiec Poznańskie lata E.T.A. Hoffmanna 180o-1802.

Wieczór autorski i promocja książki Patrycji Bukalskiej Sierpniowe dziewczęta ' 44 (Warszawa 2013), prowadzenie: dr hab. Wiesław Ratajczak, prof. UAM.

Prelekcja dr Małgorzaty Delimaty Manipulatorka, sabotażystka, wróg. Portrety obcych władczyń polskiego średniowiecza w piśmiennictwie popularnonaukowym i dydaktycznym XIX wieku.

Wieczór autorski i promocja książki Jerzego Kapusty Plus minus. Podręcznik do myślenia (Poznań 2014), prowadzenie: dr hab. Wiesław Ratajczak, prof. UAM. 
Poznański Oddział TLiAM współorganizował dwa spotkania w Teatrze Muzycznym w Poznaniu z cyklu „Krakowski Salon Poezji”: 25 października 2014 roku Andrzej Seweryn czytał Boską Komedię Dantego, zaś 22 listopada 2014 roku Anna Dymna czytała poezję Wisławy Szymborskiej.

\section{PRZEWORSK}

Prelekcja mgr Bożeny Figieli O czym mówia stare listy? Korespondencja Zygmunta Krasińskiego z rodzina Lubomirskich jako dokument obyczajowy epoki romantyzmu zorganizowana we współpracy z Pedagogiczną Biblioteką Wojewódzką im. Józefa Gwalberta Pawlikowskiego w Przemyślu (Filia w Przeworsku) w 155. rocznicę śmierci Zygmunta Krasińskiego.

\section{RZESZÓW}

Spotkanie z prof. drem hab. Czesławem Kłakiem, autorem książki Pigoń (Rzeszów 2013); dyskusję o książce prowadzili: dr hab. Kazimierz Maciąg, prof. UR oraz dr hab. Marek Stanisz, prof. UR.

\section{SIEDLCE}

Prelekcje wygłoszone w ramach otwartych zebrań naukowych Oddziału:

Dr hab. Marek Pąkciński, prof. IBL PAN, Twórczość Stefana Żeromskiego i innych modernistów $w$ świetle wspótczesnej teorii filmu

Dr Joanna Frużyńska, Hipertekstualność w literaturze elektronicznej wobec powieści nielinearnej

Dr hab. Michał Kuziak, prof. UW, Magnetyzm romantyczny: Krasiński i inni

Dr hab. Joanna Gardzińska, Nazwiska na wschodnim pograniczu dialektalnym i etniczno-językowym Polski

Dr Ewa Szczeglacka-Pawłowska, Romantyzm brulionowy. Projekt lektury

Mgr Dorota Pikula, Symbolika sceny Bożego Narodzenia

Współorganizacja wraz z Instytutem Filologii Polskiej i Lingwistyki Stosowanej Uniwersytetu Przyrodniczo-Humanistycznego w Siedlcach, Instytutem Badań Literackich PAN i Uniwersytetem Warszawskim konferencji „W soczewce. Wybrane aspekty wizualności w kulturze XIX wieku" (29-30 maja 2014).Wygłoszono osiemnaście referatów.

\section{STAROGARD GDAŃSKI}

Odczyty:

Mgr Jacek Tybinka, Polskie Państwo Podziemne oraz Churchill a Polska Mgr Tadeusz Dąbrowski, O poezji po śmierci Tadeusza Różewicza

Dr Andrzej Leszczyński, Normy i powinności moralne

Dr Sylwia Karpowicz-Słowikowska, (Nie)banalna Konopnicka Mgr Tadeusz Kubiszewski, Kwiaty ze Starogardu (o poezji Jana Majewskiego) 
Mgr Ryszard Szwoch, Literackie rocznice 2014 roku oraz Rok Oskara Kolberga i Stefana Żeromskiego (konteksty pomorskie)

Odczyty:

\section{SUWA $€$ KI}

Mgr Marek Urbanowicz, Tendencje w teatrze postdramatycznym Dr Jadwiga Nowacka, Tradycje i inspiracje literackie działalności bibliotek Dr Maria Makaruk, Współczesne inscenizacje dramatu romantycznego: „Dziady” (Wodziński, Zadara, Rychcik), „Kordian” (Kaczmarek), „Nie-Boska komedia” (Kruszczyński, Nalepa) oraz Fredro romantyczny: „Śluby panieńskie”, „Zemsta”, „Pan Jowialski”

Dr Barbara Nowacka, Poszukiwanie wspólnych korzeni kulturowych Polski i Litwy

Organizacja XIV Miejskiego Konkursu Recytatorskiego Gimnazjalistów „Młodości! Ty nad poziomy wylatuj”, poświęconego twórczości Adama Mickiewicza.

Współorganizacja XIV Miejskiego Konkursu Ortograficznego Gimnazjalistów „Mistrz Ortografii 2014”.

\section{SZCZECIN}

Prelekcje z cyklu „Wszechnica Polonistyczna” (zorganizowane we współpracy z Wydziałem Filologicznym Uniwersytetu Szczecińskiego i Zachodniopomorskim Centrum Doskonalenia Nauczycieli), zatytułowane Praca z tekstem, przeznaczone głównie dla uczniów szkół gimnazjalnych i ponadgimnazjalnych:

Dr Ewa Szczepan, Jak czytać melodramat

Dr hab. Andrzej Skrendo, prof. US, Poetyka eseju

Dr Rafał Sidorowicz, Jak powstaje blog

Dr hab. Ewa Pajewska, prof. US, Jak czytać przekłady z języka obcego

Dr hab. Jerzy Madejski, prof. US, Czytanie i pisanie dziennika. Diarystyka

Dr hab. Piotr Michałowski, prof. US, Interpretacja wiersza współczesnego

Prof. dr hab. Ewa Kołodziejek, Błędy i byki, czyli co to znaczy pisać i czytać poprawnie Dr Anna Kapuścińska, Jak zdawać egzamin maturalny

Dr Anna Ciciak, Jak się komunikować

Współorganizacja wraz z Wydziałem Filologicznym Uniwersytetu Szczecińskiego oraz Zachodniopomorskim Centrum Doskonalenia Nauczycieli konferencji „Przerabianie Żeromskiego" (2o listopada 2014 roku).

\section{TARNÓW}

W ramach projektu realizowanego we współpracy z Tarnowską Inicjatywą Oświatową oraz Państwową Wyższą Szkołą w Tarnowie zorganizowano cykl wykładów i imprez zatytułowany „Tarnowskie spotkania z Mrożkiem”: 
Wykład mgr Krystyny Głombowej Zwiazki „zabawy” Mrożka z „Weselem” Wyspiańskiego - pastisz, parodia, repryza czy arka przymierza?.

Wykład dr Anny R. Burzyńskiej Lis i reszta świata.

Sesja „Mrożek w Tarnowskim Teatrze” zorganizowana przez Studenckie Koło Przyjaciół Teatru.

Przedstawienia teatralne inspirowane twórczością Mrożka, wystawione przez grupę teatralną Państwowej Wyższej Szkoły w Tarnowie oraz Szkolne Koła Teatralne I, II i III Liceum Ogólnokształcącego w Tarnowie.

Wykład wygłoszony w ramach projektu „W trosce o język”, realizowanego wraz z Tarnowską Inicjatywą Oświatową:

Prof. dr hab. Andrzej Borowski, Retoryka jako sztuka komunikacji społecznej

\section{WA RSZAWA}

Spotkanie i dyskusja wokół książki dr Iwony E. Rusek Pragnienie, symbol, mit. Studium o „Próchnie” Wacława Berenta (Warszawa 2013), prowadzenie mgr Aleksandra Wójtowicz.

Wieczór zatytułowany „Dziady A.D. 2014”. Rozmowę poświęconą zrealizowanym w roku 2014 inscenizacjom Dziadów w reżyserii Michała Zadary (Teatr Polski we Wrocławiu), Radosława Rychcika (Teatr Nowy w Poznaniu) i Natalii Korczakowskiej (Teatr Dramatyczny w Białymstoku), połączoną z projekcją fragmentów spektakli, prowadziły dr Maria Makaruk i dr Katarzyna Sawicka-Mierzyńska.

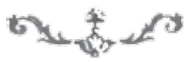

